\title{
17 \\ Simulation of a Combined Sewer Overflow Storage Tank
}

\author{
Mark Stirrup and Danielle Marchant
}

The City of Hamilton owns and operates an extensive combined sewer system (CSS) which discharges combined sewer overflows (CSOs) at up to 23 different locations during wet weather. To address the pollution from these discharges, the City has constructed five CSO storage tanks to intercept and detain overflows during periods of wet weather. During dry weather, the stored wastewater is pumped and/or drained back into the CSS and conveyed to the Woodward Avenue Wastewater Treatment Plant for treatment. The existing tanks have typically been designed to limit the frequency of CSOs to 1-3 per year, and to meet CSO control levels set out by the Ontario Ministry of the Environment's Procedure F-5-5 (MOE, 1997).

The Greenhill CSO Storage Tank was constructed in 1988 at a cost of C\$5.0 million. This was the first of Hamilton's CSO control facilities, and it was designed to control the CSO volume generated by a $15 \mathrm{~mm}$ design storm, which provides a significantly lower level of CSO control than the facilities constructed since then. The chapter discusses the historical performance of the Greenhill CSO Storage Tank in terms of the CSO frequency and volume reduction it has afforded. The performance of the CSO tank as indicated by the City's Supervisory Control and Data Acquisition (SCADA) system is compared to the simulated performance of the facility as indicated by continuous modeling with the United States Environmental Protection Agency's Stormwater Management Model Version 4.0. The performance of the CSO tank is also measured against the volumetric CSO control requirements of Procedure F-5-5 (i.e. the capture and treatment of all dry weather flow plus $90 \%$ of the volume resulting from wet weather flow). The limitations of the simulation models are also discussed.

Stirrup, M. and D. Marchant. 2002. "Simulation of a Combined Sewer Overflow Storage Tank." Journal of Water Management Modeling R208-17. doi: 10.14796/JWMM.R208-17.

(C) CHI 2002 www.chijournal.org ISSN: 2292-6062 (Formerly in Best modeling practices for Urban Water Systems. ISBN: 0-9683681-6-6) 


\subsection{Background}

The New City of Hamilton (formerly the Regional Municipality of HamiltonWentworth) operates and maintains an extensive combined sewer system (CSS). Two large interceptor sewers collect combined sewage from an area of approximately $54 \mathrm{~km}^{2}$ and convey it to the Woodward Avenue Wastewater Treatment Plant (WWTP) in Hamilton's east end (see Figure 17.1). During dry weather and small storm events, all combined sewage is conveyed to the WWTP where it receives treatment before being discharged into the eastern end of Hamilton Harbour. During large storm events, the inflows to the CSS can exceed the capacity of the interceptors and/or WWTP, and excess flows must be diverted to local receiving waters. The Region's CSS discharges combined sewer overflows (CSOs) to Hamilton Harbour, Cootes Paradise, Chedoke Creek and Red Hill Creek at up to 23 locations. These diversions are necessary in order to prevent basement flooding and ensure the interceptor sewers and Woodward Avenue WWTP are not overloaded. Typically these CSOs occur about 23 times per year (May 1 to October 31), and discharge over 4.3 million $\mathrm{m}^{3}$ untreated combined sewage to local receiving waters each year during this same period (Paul Theil Associates and Beak Consultants, 1991).

The Hamilton Harbour Remedial Action Plan (HHRAP) identified CSOs as a significant source of pollutants and recommended that the Region undertake specific measures to eliminate or minimize pollution from these discharges (HHRAP Team, 1992). To address the CSO problem, the Region completed the Hamilton-Wentworth Region Pollution Control Plan (PCP) in 1991. The recommended CSO control strategy relies heavily on off-line storage, with an associated expansion of the Woodward Avenue WWTP to achieve target reductions of CSOs to 1-4 per year on average (Paul Theil Associates and Beak Consultants, 1991). The PCP recommended the construction of ten to twelve CSO storage facilities to detain overflows during periods of wet weather. During dry weather, the stored wastewater is pumped and/or drained back into the sanitary interceptors and conveyed to the Woodward Avenue WWTP for treatment. The PCP also recommended that further improvements be gained through real time control (RTC) of automatic sluice gates and CSO storage tanks. Estimated total remediation costs ranged from C $\$ 186$ million (to achieve $4 \mathrm{CSOs} / \mathrm{yr}$ ) to $\mathrm{C} \$ 248$ million (to achieve $1 \mathrm{CSO} / \mathrm{yr}$ ). The PCP was approved by the Region's Environmental Services Committee in October 1992, and subsequently adopted by Regional Council.

The Region has made significant progress with the implementation of its PCP. Five off-line CSO storage tanks are already in operation. Their locations are indicated in Figure 17.1. Together, these facilities provide approximately 


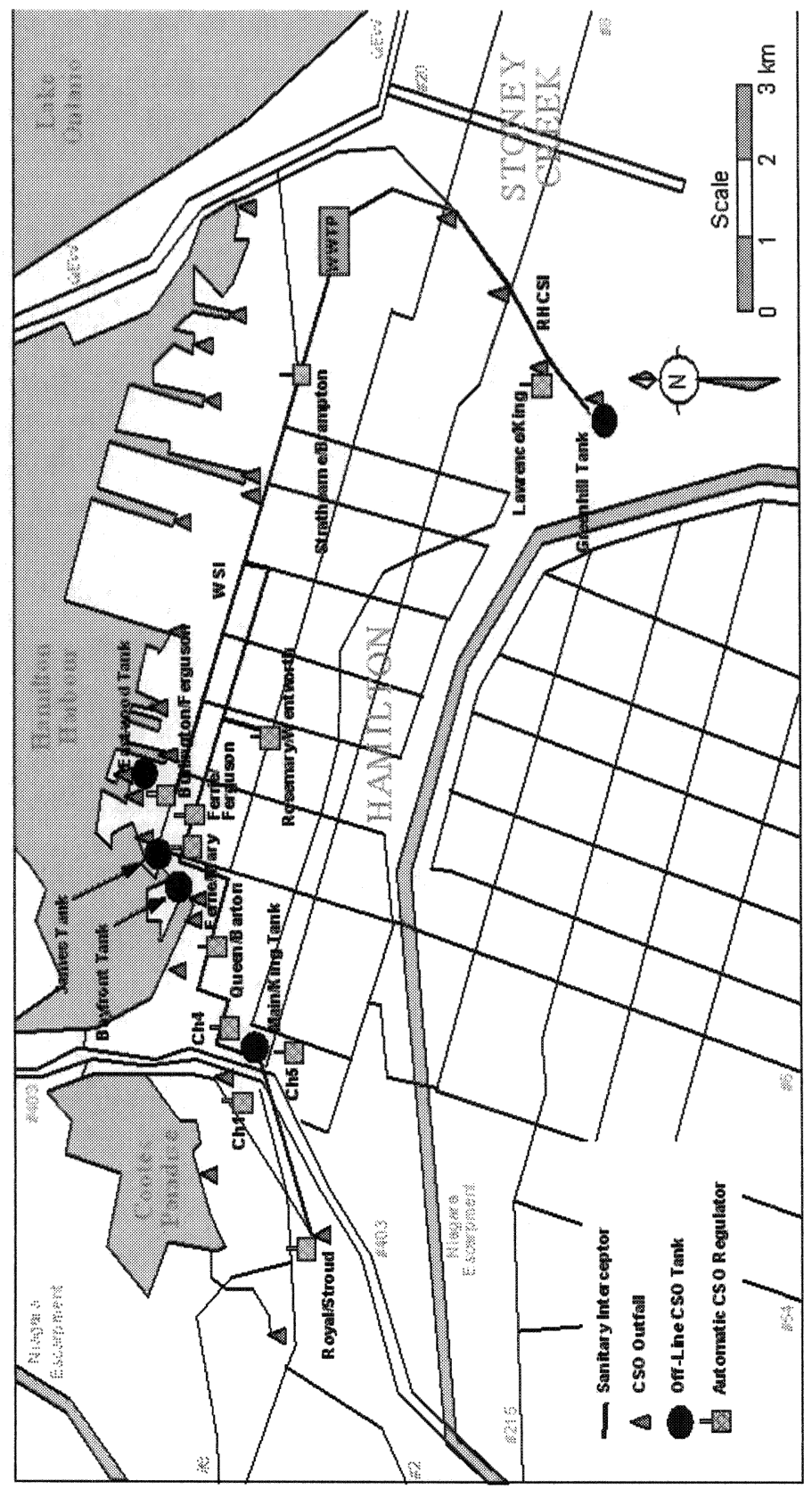

ह⿱艹⿹勹亾 
$193,000 \mathrm{~m}^{3}$ of additional CSO storage volume, and were constructed at a total cost of C\$47 million. Table 17.1 provides some details about each of these facilities, including design criteria, storage volume required to reach these criteria, and construction costs.

The objective of this chapter is to discuss the historical performance of one of these facilities in terms of the CSO frequency and volume reduction afforded. The simulated performance of the facility as indicated by continuous modeling with the United States Environmental Protection Agency's Stormwater Management Model (SWMM) Version 4.0, is compared to the observed performance of the CSO tank as indicated by the City's Supervisory Control and Data Acquisition (SCADA) system. The performance of the storage tank is also measured against the volumetric CSO control requirements of the Ontario Ministry of the Environment's Procedure F-5-5 (MOE, 1997). This procedure typically requires the capture and treatment of all dry weather flow plus $90 \%$ of the volume resulting from wet weather flow.

Table 17.1 Existing CSO storage tanks in Hamilton.

\begin{tabular}{|c|c|c|c|c|c|}
\hline Description & Greenhill & $\begin{array}{l}\text { Bayfront } \\
\text { Park }\end{array}$ & $\begin{array}{l}\text { James } \\
\text { Street }\end{array}$ & Main/King & $\begin{array}{l}\text { Eastwood } \\
\text { Park }\end{array}$ \\
\hline $\begin{array}{l}\text { Number of } \\
\text { Outfalls } \\
\text { Controlled }\end{array}$ & 1 & 2 & 1 & 3 & 2 \\
\hline $\begin{array}{l}\text { Drainage Area } \\
\text { (ha) }\end{array}$ & 1,117 & 115 & 28 & 674 & 400 \\
\hline Design Criteria & $\begin{array}{l}15 \mathrm{~mm} \\
\text { Storm }\end{array}$ & $1 \mathrm{CSO} / \mathrm{yr}$ & $1 \mathrm{CSO} / \mathrm{yr}$ & $\begin{array}{l}90 \% \text { WWF } \\
\text { Capture }\end{array}$ & $\begin{array}{l}90 \% \text { WWF } \\
\text { Capture }\end{array}$ \\
\hline $\begin{array}{l}\text { Storage } \\
\text { Volume }\left(\mathrm{m}^{3}\right)\end{array}$ & 70,000 & 20,000 & 3,200 & 75,000 & 25,000 \\
\hline $\begin{array}{l}\text { Construction } \\
\text { Cost (\$M) }\end{array}$ & 5.0 & 9.3 & 1.5 & 23.0 & 10.5 \\
\hline $\begin{array}{l}\text { Date } \\
\text { Completed }\end{array}$ & 1988 & 1993 & 1993 & 1997 & 1997 \\
\hline $\begin{array}{l}\text { Drainage of } \\
\text { Tank }\end{array}$ & Gravity & Pumping & Gravity & $\begin{array}{l}\text { Gravity \& } \\
\text { Pumping }\end{array}$ & Pumping \\
\hline $\begin{array}{l}\text { Cleaning of } \\
\text { Tank Floor }\end{array}$ & $\begin{array}{l}\text { Spray } \\
\text { Nozzles }\end{array}$ & SFTs & $\begin{array}{l}\text { Spray } \\
\text { Nozzles }\end{array}$ & SFTs & SFTs \\
\hline
\end{tabular}

\subsection{Operation of CSO Storage Tanks}

Hamilton's existing storage tanks are located in order to intercept CSOs before they enter the receiving waters. The tanks are filled by gravity and store the excess combined sewage during rain storms. When flows subside following the cessation of rainfall, the liquid contents of the tanks are drained by gravity or pumped back into the CSS and conveyed to the Woodward Avenue WWTP where they receive full (i.e. primary + secondary) treatment. 
While the liquid remains in the tanks, large volumes of solids in the combined sewage will settle to the bottom of the tank. This provides some treatment to any flow that is not fully contained by the storage facilities and must still be discharged to local receiving waters. Floating debris is retained in the tank by a system of stainless steel baffles, providing further pollutant removal and improving aesthetics within the receiving waters. When the tanks are emptied, several centimeters of solids are left on the floor of the tank. To reduce potential odours from the tanks, these solids are washed from the tank's floor by a system of spray nozzles or sediment flushing tanks (SFTs) as soon as the tanks are empty. The wash water is typically collected in a trough at the bottom of the tank and is drained by gravity or pumped back into the CSS and sent to the Woodward Avenue WWTP for treatment.

The tanks are typically designed with two separate storage cells. The first cell will completely retain the combined sewage from most rainfall events. This cell also captures the "first flush" of combined sewage which is usually the most polluted. Cell 2 is used only after Cell 1 is filled, and only a handful of events each year will fill the first cell. The two storage cell design reduces cleaning costs since Cell 2 will only require cleaning after larger storms.

A brief description of the five CSO storage tanks is presented in Table 17.1. The remainder of the chapter will concentrate on the Greenhill CSO storage tank.

\subsubsection{Greenhill CSO Tank}

Construction of the Region's first CSO storage tank, a 70,000 $\mathrm{m}^{3}$ in-line storage facility located at the east end of Greenhill Avenue, was completed in 1988 prior to the completion of the PCP, at a cost of $\mathrm{C} \$ 5.0$ million. During dry weather, sanitary sewage is conveyed via a Low Flow Channel set into the floor of the tank, through two gates which regulate the flow rate from the tank, and into the Red Hill Creek Sanitary Interceptor (RHCSI). The control gates at the end of the Low Flow Channel are motorized and can be controlled by operators at the WWTP. During wet weather, the Low Flow Channel fills and excess inflow spills into the tank proper, capturing combined sewage which would otherwise be discharged untreated to the Red Hill Creek (see Figure 17.2). The 7.5 m deep, $109 \mathrm{~m}$ diameter circular tank consists of two separate cells, providing approximately $13,000 \mathrm{~m}^{3}$ and $57,000 \mathrm{~m}^{3}$ of storage respectively. This tank was designed to retain the runoff generated by a $15 \mathrm{~mm}$ design storm. Storms of this size occur fairly frequently, and as a result the Greenhill CSO tank typically overflows about 16 times/yr (April 1 to October 31 ). The existing facility does not meet the CSO control objectives set by Procedure F-5-5. A second Greenhill CSO tank has been proposed to provide an additional $65,000 \mathrm{~m}^{3}$ of 
storage to ensure that these control levels are met in the near future. Detailed design of this facility has been completed and construction is scheduled to be completed by 2003 . The determination of the required size of this new facility was the topic of a paper presented at last year's Conference on Stormwater and Urban Water Systems Modeling (Stirrup, 2001).

Floating debris is retained in the tank by stainless steel baffles suspended from the ceiling of the tank. The tank is filled by gravity, and when inflows at the WWTP subside, the liquid contents of the tank are drained by gravity into the RHCSI and conveyed to the Woodward Avenue WWTP. Once the tank is empty, the solids which have settled to the bottom of the tank are washed from the tank's floor by a system of high pressure spray nozzles. The wash water is then drained by gravity into the RHCSI and conveyed to the Woodward Avenue WWTP.

Gates are typically completely closed when it rains, and no flow continues to the WWTP. Information used by the operator to control the rate of filling and emptying of the tank include the WWTP wet well level, the WWTP inflow rate, and the Greenhill CSO Tank inflow/outflow rates. The gates are typically closed when the WWTP wet well level exceeds $65.0 \mathrm{~m}$, when flows into the WWTP exceed 360 MLD (approximately $90 \%$ of its rated capacity), and/or depth measurement in the underflow pipe leaving the CSO tank exceeds 0.40 $\mathrm{m}$. Typically, the operators wait about 24 hours before beginning to drain the

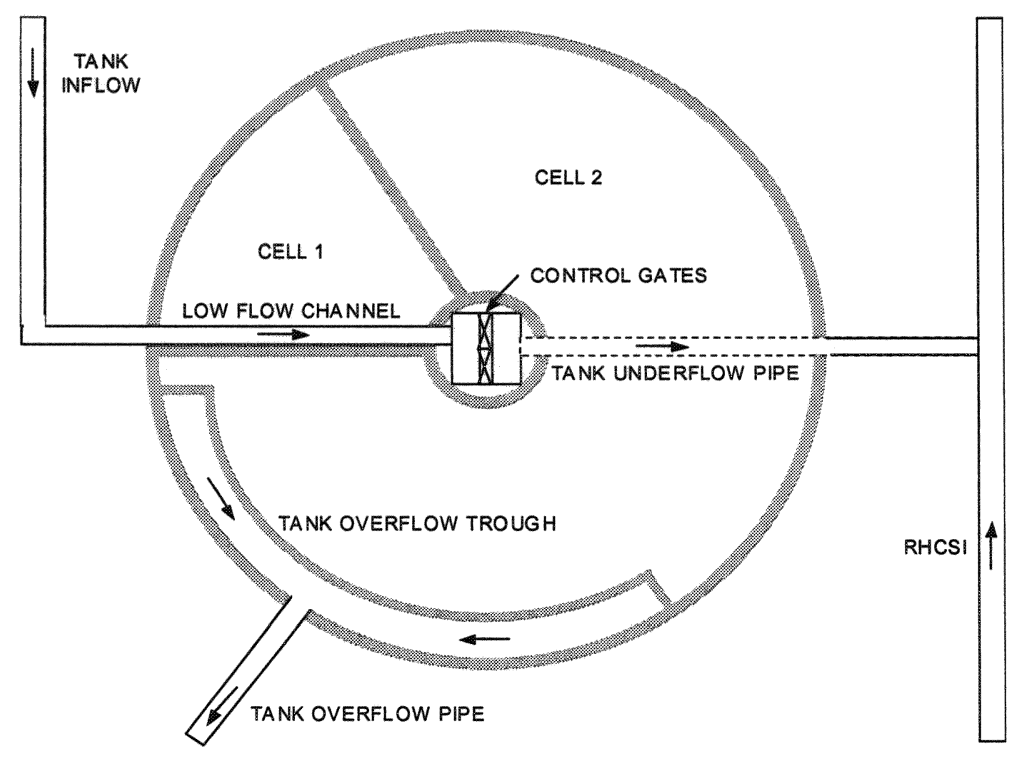

Figure 17.2 Greenhill CSO storage tank. 
tank, but this period can be longer for larger storms, or shorter for smaller storms. The Greenhill CSO Tank is typically the first of the five CSO tanks to be drained. The decision to open the gates to begin draining the tank is based upon the WWTP well level and the WWTP inflow rate. Gates are typically opened to $5 \%$ open when the wet well level drops under $65.0 \mathrm{~m}$ and/or the WWTP inflow rate drops under 320 MLD. As flows at the WWTP continue to drop, the gates are opened in increments of $5 \%$ of full range. Once the gates are $10 \%$ open, operators begin to drain the other CSO tanks. The operators may eventually fully open the gates at the Greenhill Tank.

\subsection{Simulated Performance of the Greenhill CSO Storage Tank}

The way in which the CSO storage tanks are operated can have a significant impact on the volume of CSO discharged to local receiving waters over time. Computer simulation models can be used to test and evaluate different operational strategies for filling and emptying the tanks. This is useful during preliminary design to determine the required volume of the facilities to meet long term CSO control targets, and is also useful to review the effectiveness of recent actions during real historical CSO events. Only one strategy can actually be implemented during a real event, but simulation models allow operators and engineers to evaluate a multitude of different operational approaches which could have been employed during the event which has passed. The advantage is that these strategies can be evaluated off-line without putting the real CSS and the environment at risk.

\subsubsection{Methodology}

Figure 17.3 illustrates the methodology followed to estimate the historical performance of the Greenhill CSO storage tank by computer modeling. This is essentially the same procedure followed in sizing the Main/King and Eastwood Park CSO tanks, and two proposed new CSO storage facilities to control the CSO outfalls along the Red Hill Creek.

\section{Rainfall}

The first step in simulating the performance of the CSO tank was to acquire a long term record of recorded historical rainfall data for each full year the tank has been in operation (1989-2000). In Hamilton, rainfall data are available from two nearby Environment Canada Atmospheric Environment Services (AES) 


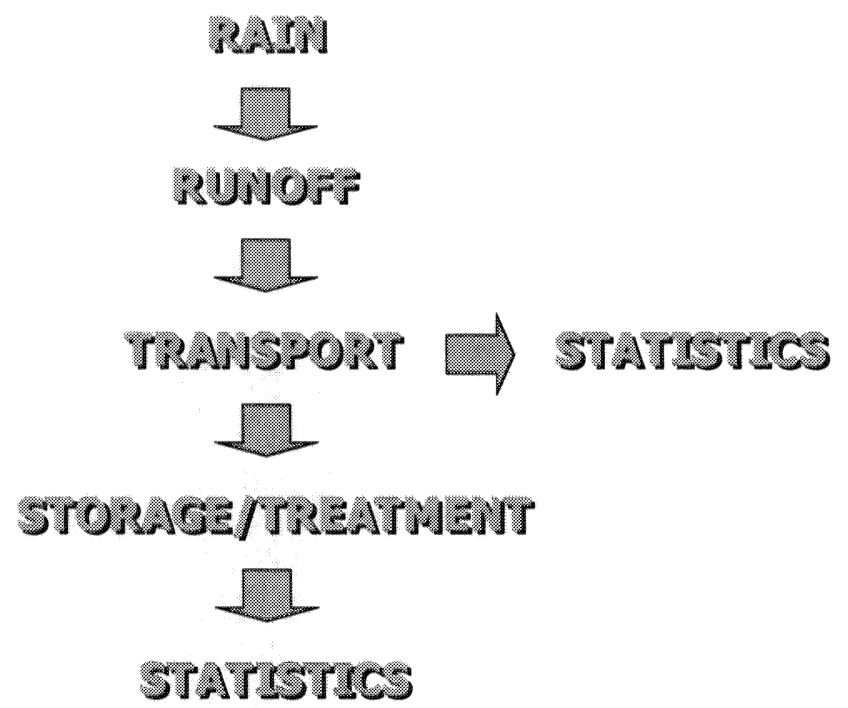

Figure 17.3 Methodology for simulating performance of Greenhill CSO storage tank.

raingauges located at Mount Hope Airport south of Hamilton's CSS and the Royal Botanical Gardens in Burlington, at the west end of Hamilton Harbour. Data are generally available at a 60 -minute timestep from these stations, which have been operating since 1970. The Region also operates a number of raingauges in and around Hamilton's CSS. Many of these stations have been operational since the tank's first full year of operation in 1989, and data are generally available at timesteps as small as 1-minute. Hourly rainfall records from the AES raingauges, and 15-minute records from the Region's Mount Hope Airport and Garth Street raingauges (the stations closest to the Greenhill CSS) were processed by the SWMM Rain module for input to the Runoff module. Each year's simulation spanned the period from April 1 to October 31, as specified by Procedure F-5-5. Measured average annual rainfall (April 1 to October 31) during the period from 1989 to 2000 was $507 \mathrm{~mm}$. Maximum and minimum annual rainfall volumes during this period were $796 \mathrm{~mm}$ and $251 \mathrm{~mm}$ respectively.

\section{Runoff}

The SWMM Runoff model for the Greenhill CSS drainage basin was based upon the original calibrated model developed by the consultant for the PCP (Paul Theil Associates and Beak Consultants, 1991). The hydrologic model of the 
Greenhill CSS includes eight subcatchments with a total drainage area of approximately $1,260 \mathrm{ha}$. The Runoff model for the basin includes no conduits. All combined sewers and diversion structures are simulated in the SWMM Transport module. Runoff module simulations were completed for each full year the that the tank has been in operation (i.e. 1989-2000). As only the period from April 1 to October 31 was required, each year was simulated separately. SWMM interface files were created for each year for subsequent input to the Transport module. The continuous Runoff simulations also provided the total WWF entering the Greenhill CSS over each year (see Table 17.2). In addition to capturing all DWF, $90 \%$ of this WWF must be controlled to meet Procedure F-5-5 (Ontario Ministry of the Environment, 1997). In other words, the CSO volume from the CSO tank should be less than or equal to $10 \%$ of this WWF volume.

\section{Transport}

Again, the SWMM Transport model of the Greenhill CSS was based upon the original calibrated model developed by the consultant for the PCP. Before using the model again, simulated dry weather flows were recalibrated against recent flow measurements and updated in the model. The Greenhill CSS includes no automatic WWTP-controlled regulator gates, and only 1 simple diversion structure located at the very upstream end of the catchment. This structure was modeled, but it has little impact on the flows conveyed to the Greenhill CSO Tank.

SWMM interface files from the Transport module simulations were created for input to the Storage/Treatment and Stats modules. Stats was used to separate the events arriving at the CSO tank for each year. This provides a basis for computing the historical reductions in CSO frequency and volume afforded by the existing Greenhill CSO tank. Table 17.2 presents the results of the continuous Transport module simulations for the years 1989-2000. The simulations indicated that on average, the existing Greenhill CSO Tank was at least partially filled 38 times per year (April - October). The corresponding average annual inflow volume was estimated to be just over 2.0 million $\mathrm{m}^{3}$.

\section{Storage/Treatment}

The operation of the tank, specifically when and how quickly its is drained, plays an important role in the level of CSO control it provides. The Storage/ Treatment module provides two parameters to control the drainage of the tank. The first parameter presets the duration of time that the CSO is detained in the storage tank before any of its contents are drained following a storm. A counter is set to the given value and begins decreasing only after all inflow to the storage 
Table 17.2 Results of SWMM Runoff/Transport/Storage Treatment simulations.

\begin{tabular}{|c|c|c|c|c|c|c|c|c|}
\hline \multirow[b]{2}{*}{ Year } & \multirow{2}{*}{$\begin{array}{l}\text { WWF } \\
\text { Volume } \\
\left(\mathrm{m}^{3}\right)\end{array}$} & \multicolumn{2}{|c|}{ CSO Tank Inflow ${ }^{2}$} & \multicolumn{2}{|c|}{ CSO Tank Overflow ${ }^{3}$} & \multirow{2}{*}{$\begin{array}{l}\text { CSO Frequency } \\
\text { Reduction } \\
(\%)\end{array}$} & \multirow{2}{*}{$\begin{array}{l}\text { CSO Volume } \\
\text { Reduction } \\
(\%)\end{array}$} & \multirow{2}{*}{$\begin{array}{l}\text { WWF Volume } \\
\text { Controlled } \\
(\%)\end{array}$} \\
\hline & & $\begin{array}{l}\text { Frequency } \\
\text { (\# Events) }\end{array}$ & $\begin{array}{c}\text { Volume } \\
\left(\mathrm{m}^{3}\right)\end{array}$ & $\begin{array}{l}\text { Frequency } \\
\text { (\# Events) }\end{array}$ & $\begin{array}{c}\text { Volume } \\
\left(\mathrm{m}^{3}\right)\end{array}$ & & & \\
\hline 1989 & 1989 & 40 & $1,841,140$ & 15 & 884,210 & 63 & 52 & 56 \\
\hline 1990 & 1990 & 44 & $2,537,400$ & 22 & $1,445,300$ & 50 & 43 & 47 \\
\hline 1991 & 1991 & 34 & $1,676,100$ & 13 & 710,300 & 62 & 58 & 60 \\
\hline 1992 & 1992 & 43 & $2,971,000$ & 20 & $1,688,900$ & 53 & 43 & 45 \\
\hline 1993 & 1993 & 45 & $1,946,800$ & 11 & 935,640 & 76 & 52 & 55 \\
\hline 1994 & 1994 & 36 & $1,768,600$ & 18 & 586,020 & 50 & 67 & 68 \\
\hline 1995 & 1995 & 34 & $2,065,800$ & 16 & $1,127,500$ & 53 & 45 & 72 \\
\hline 1996 & 1996 & 39 & $3,346,400$ & 24 & $2,361,600$ & 38 & 29 & 33 \\
\hline 1997 & 1997 & 45 & $1,495,800$ & 15 & 504,150 & 67 & 66 & 68 \\
\hline 1998 & 1998 & 33 & 877,850 & 5 & 156,600 & 85 & 82 & 83 \\
\hline 1999 & 1999 & 35 & $1,579,100$ & 15 & 792,440 & 57 & 50 & 52 \\
\hline 2000 & 2000 & 31 & $1,933,400$ & 15 & $1,086,600$ & 52 & 44 & 46 \\
\hline Total & Total & 459 & $24,039,390$ & 189 & $12,279,260$ & & & \\
\hline Average & Average & 38 & $2,003,283$ & 16 & $1,023,272$ & 59 & 49 & 55 \\
\hline
\end{tabular}

Notes: ${ }^{1}$ Computed by Runoff

${ }^{2}$ Computed by Transport

${ }^{3}$ Computed by Storage/Treatment 
tank ceases. If inflow to the tank resumes before the counter reaches zero, the counter is reset to its original value. When the counter reaches zero, drainage of the tank begins according to preset operational parameters. The second parameter allows the user to preset the mode and rate of drainage from the tank, once drainage begins. Tank drainage rates can be described by a flow versus depth relationship or by a power equation.

A Storage/Treatment model of the Greenhill CSO tank was created. CSO detention times and tank drainage rates were selected after interviews with the operators at the WWTP to determine typical operating strategies for the facility. The Storage/Treatment module requires that these parameters be preset prior to each simulation, and that they remain constant throughout each simulation. Operators will generally begin draining this CSO tank before the four other facilities, but only once wet weather flows to the Woodward WWTP have receded to levels where this additional flow can be accommodated by the plant. For most events, this typically takes 12-24 hours, but has often taken longer for very large storms or snowmelt events. Normal operation of the tank entails waiting 24-48 hours before beginning to empty it following a storm, and the tank has been designed to permit its drainage from full volume in $24-48$ hours. The tank is drained by gravity through two motorized sluice gates controlled from the WWTP via the SCADA system. With the gates fully open, the tank can be drained from full in about 8 hours.

\subsubsection{Simulated Performance}

The Storage/Treatment model was run for each full year the tank has been in service. The period simulated during each year was April 1 to October 31, as specified by Procedure F-5-5. Input to the Storage/Treatment simulations was provided by the SWMM interface files generated by their respective Transport module simulations. CSO frequencies and volumes generated by these simulations are summarized in Table 17.2. This table also presents the corresponding CSO frequency and volume reductions, and WWF control levels provided by the existing storage tank. On average, the existing Greenhill CSO Tank reduces the number of CSO events from 38/yr to 16/yr (a 59\% improvement), and reduces the corresponding volume of CSO from $2.03 \mathrm{~m}$ $\mathrm{m}^{3} / \mathrm{yr}$ to $1.02 \mathrm{~m} \mathrm{~m}^{3} / \mathrm{yr}$ (a $49 \%$ improvement). The simulations also indicate that the facility typically controls approximately $55 \%$ of the WWF entering the Greenhill CSS.

Table 17.3 compares the computed performance of the existing Greenhill CSO Tank with the observed performance of the facility in 2000 . The observed performance of the tank was determined from historical records archived by the City's SCADA System. Overflow from the tank is via a $3.07 \mathrm{~m}$ high $\mathrm{x}$ 
$4.25 \mathrm{~m}$ wide corrugated steel pipe-arch sewer. Observed event CSO rates and volumes were computed from measured depths at the entrance to this sewer using Manning's equation. The SCADA system recorded $17 \mathrm{CSO}$ events between April 1 and October 31, 2000, with a total CSO volume of 1,310,550 $\mathrm{m}^{3}$, while SWMM computations estimated 14 CSO events with a total CSO volume of $1,086,500 \mathrm{~m}^{3}$ for the same period. The SWMM computations appear to underestimate the frequency and volume of CSOs from the existing Greenhill CSO storage facility. Some possible explanations are discussed below.

Table 17.3 Simulated versus observed performance of Greenhill CSO storage tank for 2000.

\begin{tabular}{ccccc}
\hline & \multicolumn{2}{c}{ Observed CSO } & \multicolumn{2}{c}{ Simulated CSO } \\
\cline { 2 - 5 } Date & $\begin{array}{c}\text { Duration } \\
\text { (Hours) }\end{array}$ & $\begin{array}{c}\text { Volume } \\
\left(\mathrm{m}^{3}\right)\end{array}$ & $\begin{array}{c}\text { Duration } \\
\text { (Hours) }\end{array}$ & $\begin{array}{c}\text { Volume } \\
\left(\mathrm{m}^{3}\right)\end{array}$ \\
\hline $04-08-00$ & 11 & 5,605 & - & - \\
$04-20-00$ & 31 & 32,735 & 22 & 34,100 \\
$05-10-00$ & 65 & 190,035 & 32 & 113,000 \\
$05-18-00$ & 30 & 19,738 & - & - \\
$05-24-00$ & 14 & 9,260 & - & - \\
$06-09-00$ & - & - & 5 & 101,000 \\
$06-11-00$ & 120 & 519,570 & 86 & 238,000 \\
$06-21-00$ & 36 & 55,969 & 7 & 54,700 \\
$06-25-00$ & 41 & 64,088 & 5 & 23,500 \\
$06-29-00$ & 11 & 32,718 & - & - \\
$07-09-00$ & 11 & 19,738 & 5 & 61,900 \\
$07-14-00$ & 6 & 7,310 & 5 & 35,200 \\
$07-30-00$ & 35 & 109,991 & 86 & 165,000 \\
$08-09-00$ & - & - & 5 & 90,500 \\
$08-16-00$ & - & - & 3 & 1,570 \\
$08-23-00$ & 8 & 9,503 & - & - \\
$09-09-00$ & 14 & 94,733 & 5 & 40,200 \\
$09-14-00$ & 23 & 34,115 & - & - \\
$09-23-00$ & 36 & 64,745 & 20 & 52,700 \\
$10-04-00$ & 29 & 40,694 & 52 & 75,100 \\
Total & 521 & $1,310,547$ & 338 & $1,086,470$ \\
\hline
\end{tabular}

\subsection{Limitations of SWMM and Batch-Oriented Modeling}

The SWMM models of the Greenhill CSS and CSO Tank proved to be a useful tool in determining the required volume of a second Greenhill CSO storage tank to meet the volumetric CSO control requirements of Procedure F-5-5 (Stirrup, 
2001), but their effectiveness in simulating the day to day performance of the existing facility is limited by a number of factors, which can be summarized as follows:

1. SWMM Transport does not permit the modeler to accurately simulate the movement of dynamic CSO regulators (i.e. motorized sluice gates) which determine the rate and amount of CSO diverted into the existing CSO tanks. The threshold of a CSO regulator (i.e. the apportioning of undiverted and diverted flows) can be varied based upon the incoming flowrate at the same CSO regulator, but it cannot be varied with time, and it cannot be varied based upon the incoming flowrate at other locations within the system. For example, this does not allow the control of dynamic CSO regulators based upon flowrates at the WWTP where the control of such structures is typically directed from.

2. SWMM Storage/Treatment does not permit the modeler to vary CSO storage detention times within a single simulation. The detention time can be varied from one simulation to another, but once it is set, the same detention time is applied to every event in the simulation. This does not accurately represent the real, physical operation of the CSO storage tanks over long periods of time.

3. SWMM Storage/Treatment does not provide the modeler with the necessary flexibility to vary CSO tank drainage rates. CSO tank drainage rates can be varied based upon the depth of sewage in the same tank, but cannot be varied with time, and cannot be varied based upon flowrates within the CSS and/or at the WWTP.

4. Neither program permits the modeler to accurately simulate the control of in-line storage facilities, or combined in-line and offline storage facilities.

5. The simulation approach described above is essentially a batch oriented one, where none of the results of the simulation are available until the entire simulation is completed. This approach does not adequately support engineering analysis of operation aspects in CSS, and it is difficult, if not impossible to implement simulation of operator intervention within the CSS.

In this case, neither the SWMM Transport and Storage/Treatment modules nor the batch oriented simulation approach they require, provide the means to accurately represent the operation of dynamic CSO regulators and CSO storage tanks in real time because operational parameters must be set prior to, and remain constant throughout the entire simulation period. 
These are significant limitations. It is important that the simulations accurately represent the real-world operation of CSO regulator gates and storage tanks, for each and every storm. If the real, physical mode of operation of the gates and/or tanks varies significantly from storm to storm, or within individual storms themselves, the benefits gained by continuous hydrologic modeling will be outweighed by the operational limitations introduced by the batch-oriented simulation approach.

Some other considerations include:

1. The spatial resolution and accuracy of the rainfall available or chosen for the simulation can have a significant impact on the hydrologic model and resulting CSO frequencies and volumes.

2. The temporal resolution of the rainfall can also impact the accuracy of the hydrologic model and resulting CSO frequencies and volumes. Rainfall recorded at larger timesteps may tend to underestimate peak flows and to some extent, CSO volumes. However, long-term rainfall records at timesteps smaller than 60 minutes are rarely available.

3. The response of a CSS is highly dependent upon the flows which reach its overflow regulators, and as such the shape or peakiness of the storm event and the resulting flow hydrographs can have a significant impact on the simulated CSO volume and frequency and on the CSO tank volume required to meet volumetric control targets. This can be affected by the size of the rainfall or simulation timestep, or the accuracy of the hydrologic model.

4. CSO tanks need to be emptied following wet weather to be fully effective in controlling subsequent events. If a tank is not completely empty prior to a storm, its effective storage capacity is reduced and so is its ability to control a CSO event. Two or more smaller storms can cause a tank to fill and overflow, even if the CSO volume generated by each storm is smaller than the volume of the storage tank.

\subsection{The Need for Dynamic Modeling}

The operation and performance of a CSS can only be accurately represented if the hydraulic simulation tools permit realistic operation of the dynamic components within the CSS. Hydraulic simulation models which are to be used to address operational aspects of sewer systems, such as the operation of dynamic CSO regulator gates and storage tanks should be flexible. They should 
offer the ability to configure, manipulate, modify and monitor all elements of the sewer system including both static and dynamic control structures.

To properly simulate supervisory control of the CSS by plant operators, hydraulic simulation models should permit the user to directly manipulate all dynamic control elements in the same way that the SCADA system permits them to operate the CSS during a real event. In order to simulate automatic RTC, the models must provide the user with built-in RTC strategies and/or tools to develop new RTC strategies. In this case, the model must be able to execute these control strategies as the simulation progresses without any user intervention, although the user should be able to monitor the control actions implemented by the program.

\subsection{Review of Hamilton's CSO Control Program}

Hamilton's existing PCP is now nearly 10 years old. The City of Hamilton has recently secured funding from Environment Canada's Great Lakes Sustainability Fund for a study to consider recent advances in CSO control technology and to update the City's CSO Control Program to ensure it meets all the requirements of Procedure F-5-5. The study will include a thorough review of the City's existing CSS maintenance programs, investigation of innovative options for CSO control including on-site storage and treatment options and operational improvements, and development of a new CSO Control Implementation Program for the City of Hamilton, which includes a sustainable funding program and implementation schedule. Work has already begun on the study, and the new CSO Control Implementation Program is scheduled to be completed by June 2002.

The operation of the existing CSO storage tanks is an important aspect of the CSO control program. Dynamic computer simulation models will be employed to review the impact of different CSO storage tank drainage rates and volumes on the Woodward Avenue WWTP and investigate different strategies for emptying the facilities following storm events. This analysis will be completed using the new dynamic simulation models developed for Hamilton's RTC System (Stirrup and Vitasovic, 1998). Winstdy offers the ability to simulate the operation of dynamic CSO regulators and storage tanks in real time. Simulations can be momentarily paused while any number of operational changes are made, and then resumed to view the response of any portion of the CSS to these changes. Graphs show the effects of control decisions on CSOs conveyed to the WWTP and to receiving waters, and the impacts on hydraulic grade lines within the CSS. 
The program offers a number of simple control strategies which can be selected and configured to simulate the automatic operation of dynamic sewer system elements within the CSS. More complex RTC strategies, based upon mathematical optimization have also been developed (Stirrup and Vitasovic, 1998). The capability to directly manipulate CSS elements during the simulation makes the program especially well suited for simulation of automatic and supervisory RTC. It also provides an invaluable post-processing tool which allows engineers and operators to evaluate the impacts of any number of different operating strategies following an event or series of events. This permits engineers and operators to develop and thoroughly evaluate potential operating strategies prior to implementation, without placing the CSS and WWTP at risk.

\subsection{Summary}

A simple approach was used to simulate the performance of one of the City's existing CSO storage tanks over time. The methodology employed long-term continuous simulation using the USEPA SWMM Rain, Runoff, Transport, Storage/Treatment and Stats modules to estimate the performance of the Greenhill CSO storage tank.

The continuous SWMM Transport and Storage/Treatment modules are useful CSO planning and preliminary design tools which can be used to size proposed CSO storage facilities and to demonstrate their ability to meet the requirements of MOE Procedure F-5-5 over the long-term. However, these models have some significant limitations when attempting to simulate the longterm operation of existing CSO storage tanks, where the mode of operation of these facilities may change from one storm to another, or within a single storm. This is because these models lack the features and flexibility to accurately represent the many different ways motorized CSO regulator gates and storage tanks can be controlled by operators or by today's computerized SCADA systems. In some cases, this is because operational processes are simply not included in the models, but more often than not it is because the models do not offer the ability to realistically vary operational processes and/or parameters in real time.

The solution is the development and employment of more dynamic sewer simulation models. 


\section{References}

Hamilton Harbour RAP Team, 1992. Remedial action plan for Hamilton Harbour goals, options and recommendations: volume 2 - main report. ISBN No. 0-77780533-2.

Ontario Ministry of Environment, 1997. Procedure F-5-5 - Determination of treatment requirements for municipal and private combined and partially separated sewer systems, December 1997.

Paul Theil Associates and Beak Consultants, 1991. Regional Municipality of Hamilton-Wentworth pollution control plan. Prepared for the Regional Municipality of Hamilton-Wentworth, Hamilton, Ontario.

Stirrup, M. and Z. Vitasovic, 1998. Hamilton real time combined sewer overflow control. Proceedings of the StormWater Assessment Monitoring and Performance (SWAMP) Program Stormwater/CSO Technology Transfer Conference, February 1998, Toronto, Ontario.

Stirrup, M. 2001. "Sizing a New CSO Storage Tank using Continuous SWMM." Journal of Water Management Modeling R207-19. doi: 10.14796/JWMM.R207-19. 